\title{
Research on the Restrictive Factors and Coping Strategies of Audit Quality Improvement
}

\author{
Weishuang $\mathrm{Xu}^{1, \mathrm{a}}$, * \\ ${ }^{1}$ College of Economics and Management, Qilu Normal University, Jinan, Shandong, China \\ axwsjn@163.com
}

Keywords: Audit Quality; Improvement; Restrictive Factors; Coping Strategies

\begin{abstract}
High quality information plays a vital role in guiding investors to make investment decisions and optimize resource allocation. But the agency problem and information asymmetry problem that leads to different investors can obtain the information quality is different. So it is necessary to reexamine the quality of information, and Certified Public Accountant (CPA) audit is the behavior of reexamining the quality of accounting information. Due to the imperfect development of CPA industry in our country, there is still a certain gap between the audit quality of CPA and the due expectation quality. Therefore, on the basis of discussing the factors that restrict the improvement of audit quality, this paper intends to put forward the coping strategies to improve the audit quality from the perspective of audit subject, the audited entity and audit supervision environment combine with the status quo of audit quality in our country. Expect to promote the healthy development of China's CPA industry.
\end{abstract}

\section{Introduction}

High quality information plays a vital role in guiding investors to make investment decisions and optimize resource allocation. But the agency problem and information asymmetry problem that leads to different investors can obtain the information quality is different. As an important component of enterprise information, the quality of accounting information not only affects the establishment or termination of managerial fiduciary responsibility, but also affects the resource allocation efficiency in capital market. So it is necessary to reexamine the quality of accounting information, and Certified Public Accountant (CPA) audit is the behavior of reexamining the quality of accounting information. In view of the special role of audit, the importance of audit quality is self-evident. High quality auditing can reduce the problem of principal-agent and information asymmetry, reduce the transaction costs of both parties, and improve the efficiency of resource allocation. Due to the imperfect development of CPA industry in our country, there is still a certain gap between the audit quality of CPA and the due expectation quality. In this context, it is of great practical significance to discuss the restrictive factors of audit quality improvement and put forward targeted coping strategies.

\section{Overall Evaluation of Audit Quality in China}

The Current Situation of CPA Industry in China. According to the data provided by China Certified Public Accountants Industry Management Information System, there were 8528 accounting firms in China by September 2017. (1) The size of the firm is mainly small and medium-sized. All the firm only 40 firms with securities and futures industry qualification, the number of CPAs more than 50 people have a total of 187 firms, more than 10 people have 3471 firms and more than 5 people have 6638 firms. Small and medium-sized firms become the subject of the firm. (2) The Chinese Institute of Certified Public Accountants currently has 124819 non practicing members and 102909 practicing members. Compared with 8528 CPA firms, the average number of CPAs in each firm is only 12. (3) The organizational form of the firm is mainly limited liability. Of all 8528 firms, 742 were the special general partnership system, 2380 were based on the partnership and 6148 of the other were in the form of limited liability. 
The Definition and Evaluation of Audit Quality. With regard to the definition of audit quality, different scholars have conducted different studies based on different perspectives. DeAngelo (1981) [1] first defines the audit quality. She considers that audit quality is the ability of the auditor to discover and eliminate the misstatement of the financial statements, which depends on the combination of the professional competence and independence of the auditor. Palmrose (1986) [2] argues that audit quality is the level of assurance that financial statements do not include significant omissions or errors. In February 2014, the International Federation of Accountants (IFAC) and International Auditing and Assurance Standards Board (IAASB) presented five major factors that influence the quality of audits, namely, inputs, processes, outputs, financial reporting supply chains and audit environments. Li Yan(2017) [3] discusses the measurement of audit quality on the perspective of before, present and subsequent. Sum up the study of domestic and foreign scholars: (1) the audit quality depends not only on the professional competence and independence of the auditor, but also on the assurance degree of the auditor's audit results. (2) The factors that affect the audit quality are procedural and systematic, and any attempt to evaluate the quality of audit with a single indicator is flawed.

The Present Situation of Audit Quality in China. Generally speaking, the audit quality of our country is still worthy of affirmation. The practice ability and moral quality of auditors are gradually improved, but the incident of audit subject punished also occurred from time to time. (1) The audit quality is rising step by step, but there is still some fluctuation. According to the information released by the Chinese Institute of Certified Public Accountants, the proportion of non-standard auditors' opinions issued by accounting firms for the year of 2014-2016 was 3.67\%, $3.66 \%$ and $3.34 \%$ respectively, while the annual growth rate of audit fees for the year of 2014-2016 was $6.00 \%, 7.60 \%$ and $8.16 \%$ respectively. According to the view that non-standard audit opinions and audit fees are positively related to audit quality, the audit quality of China's accounting firm is worthy of recognition although there is a certain range of fluctuations. (2) The number of CPAs punished has substantially reduced. Liu Ruo Chen (2017) [4] founds that there are total 12 penalties on accounting firms issued by China Securities Regulatory Commission(CSRC) for the year of 2013-2016 through analyzing the administrative penalty notices announced by CSRC. The decline of penalty number is obvious compared with that of 2000 an average of about more than 10 penalties. (3) The absence of professional ethics of CPAs is worthy of attention. Liu Ruochen (2017) thinks that the most frequent occurrence of CPAs' punishment is that CPAs are not diligent and responsible, while the lack of professional competence of CPAs and other reasons is very rare. This shows that although CPA has the ability to provide high quality audit services, but the impact of professional ethics lack can not be ignored.

\section{The Main Factors That Restrict the Improvement of Audit Quality}

Restriction of Audit Subject. The restriction of audit subject on audit quality can be discussed from accounting firms and CPAs. (1) Based on the level of accounting firms. The impact of accounting firms on audit quality is mainly reflected in the firms' expertise, size and organization form. It is generally believed that the firms' expertise, size and partnership form are positively related with the audit quality (Dong Xiuqin, Liu Muhua, 2010[5]; Wu Min, 2017[6]; Firth et al., 2012[7]; Kong Ningning, Li Xue, 2016[8]). However, the reality of China's accounting firms based on small and medium-sized and limited liability determines that accounting firms do not have advantages in these areas. (2) Based on the level of CPAs. The impact of CPA on audit quality is mainly reflected in the professional ethics level, professional competence and experience, risk awareness and reputation. However, the reality of the majority of accounting firms in our country do not have a large number of CPAs determines the promotion of CPAs in these areas still has great difficulties.

Restrictions of the Audited Entity. The restriction of audited entity on audit quality is mainly reflected in the perfection of corporate governance structure and internal control system. (1) Perfection degree of corporate governance structure. The more perfect the corporate governance structure, the higher the audit quality (Pan Qi, Wen Quan, 2017) [9]. The ideal corporate 
governance structure is that can make the client, management and CPA to check and balance each other in the auditing tripartite relationship. But the reality is that the management is in a relatively dominant position in the auditing tripartite relationship due to the absence of client. In this case, the financial statements provided by management will be audited by the CPAs also entrusted by management, which in some way will affect the audit independence and also affect the audit quality. (3) Perfection degree of internal control system. The higher the enterprise internal control is, the higher the audit quality is (Jiang Yaoming, Xiao Jie, Zhang Lin, one, 2017) [10]. The internal control system not only affects the formation of accounting information, but also affects the scope and focus of audit. However, the internal control of many enterprises has not really played a role. The main reason for this is that the internal control system is formulated by the management leadership. It may affect the interests of management if the internal control system is strictly enforced. Management will be to some extent above the internal control system in order to safeguard their interests.

The Restriction of Audit Supervision Environment. The audit supervision environment mainly refers to the practice environment with the legal and administrative constraints. The improvement of audit supervision environment will provide a strong impetus for high quality audit supply and demand. (1) Restriction of audit supervision environment on audit subject. At present, the main risk of audit subject in China comes from the risk of the punishment of regulatory authorities rather than litigation risk. Litigation risk is an important driving factor to improve the audit quality. The main reason for this is the weakening of civil procedural mechanism and the lack of legal enforcement. Which makes the legal punishment of audit failure relatively weak compared with the economic benefits obtained by the audit subject. Therefore, under the guidance of the government, administrative punishment has become the main way of risk taking by the audit subject. (2) Restriction of audit supervision environment on high quality audit supply and demand. The weakening of audit supervision environment will affect the effectiveness of the market, so that the market may not be able to effectively identify the audit quality. But in general, high quality audit services on both sides of supply and demand are required to pay a higher price. If the market can not provide effective compensation to the parties who pay more in the long term, it will lead low quality audit expel high quality audit. Low quality audit supply and demand will be the dominant in the audit market.

\section{The Coping Strategies of Improving Audit Quality}

Based on the Perspective of Audit Subject. The audit subject is the key factor affecting the audit quality. Therefore, the improvement of audit quality requires the audit subject to perfect itself. (1) Further enhance the firm's professional expertise on the basis of expanding the size of accounting firms. The firm's size and industry expertise both have a positive impact on the audit quality, and the combination of the two will further reinforce this positive impact. Expansion of accounting firm size can be carried out through the merger and joint of accounting firms. The professional division of labor can be performed when the firm scales develop to a certain extent. So the firm can do fine and promote itself industry expertise on a large size. (2) Promote the reform of organizational form of accounting firm. The special general partnership creates legal liability and audit risk to the individual of CPA, transforms the limited liability into unlimited liability and increases the cost of non-compliance of the auditor. So the CPA may become more independent and prudent to improve the audit quality. (3) Enhance the professional competence and professional ethics level of CPA. On the one hand, the professional competence of CPAs can be improved through the qualification restriction, follow-up education system and exchange training among peers etc. On the other hand, the professional ethics level of CPA with independence as the core can be improved through the improvement of reputation mechanism.

Based on the Perspective of Audited Entity. It is necessary to improve the corporate governance structure and internal control system based on the perspective of audited entity to improve the audit quality. (1) Perfect corporate governance structure. The key to improve the corporate governance structure include the following two aspects. One is to further improve the 
audit tripartite relationship, strengthen the relationship between the client and the CPAs and weaken the relationship between management and CPAs. This will make management greatly reduce the possibility of audit purchase behavior. The other is to weaken the control behavior of accounting information generation conducted by management, as much as possible to reduce the effect of management fraud on audit quality under the sampling audit. (2) Improve the internal control system. The relatively perfect of internal control system of the audited entity can bring the following advantage. On the one hand, which will make company's business processes and the allocation of rights and responsibilities form mutual supervision and restriction system, and further reduce management fraud. On the other hand, this will reduce the degree of information asymmetry and improve the transparency of accounting information. The reduction of management fraud and the promotion of information transparency are beneficial to the improvement of audit quality.

Improve the Audit Supervision Environment. The main purpose of the improvement of audit regulatory environment is to create a high quality audit supply and demand environment through the improvement of market. (1) Improve the legal and administrative regulatory environment for auditing. The perfection of legal environment mainly refers to enhance the deterrent force of law by increasing the punishment of illegal acts, thus increasing the tangible cost of CPA's illegal behavior. The improvement of administrative supervision environment mainly refers to the government departments and the Chinese Institute of Certified Public Accountants continue to strengthen the administrative penalty and industry self-discipline constraints, thereby increasing the invisible costs of CPA's illegal behavior. Of course, due to the improvement of legal environment can reduce government's intervention in the development of the audit industry. So the perfection of legal environment is more urgent and necessary. (2) Improve related parties' power for high quality audit. After the reorganization and restructuring, the organization form reform, the firm bigger and stronger strategy and the entry of foreign capital, the competition between the firms has become increasingly fierce. Harsh competition makes the accounting firms must rely on the provision of high quality audit services to survive and develop. At the same time, after the improvement of audit supervision environment, rational investors will find that only the pursuit of high quality audit services is an effective way to safeguard their own interests.

\section{Reference}

[1] DeAngelo, L. Auditor Size and Audit Quality [J]. Journal of Accounting \& Economic, 1981(03).

[2] Palmrose Z. Audit Fees and Auditor Size: Further Evidence [J] Journal of Accounting Research. 1986, 24(1).

[3] Li Yan. Research on the Relationship between Audit Quality and Resource Allocation Efficiency from the Perspective of Media Coverage [D]. Beijing: Beijing Jiaotong University, 2017.

[4] Liu Ruochen. An Analysis of Auditing Quality of Certified Public Accountants in China [J]. Journal of Xinyang Agriculture and Forestry University, 2017(06).

[5] Dong Xiuqin, Liu Muhua. Industry Expertise and Audit Quality: An Empirical Study Based on the Perspectives of Investors and Financial Reporting [J]. Securities Market Herald, 2010(04).

[6] Wu Ming. Firm Size, Industry Expertise and Audit Quality [J]. Communication of Finance and Accounting, 2017(08).

[7] Firth M, Mo P L L, Wong R M K. Auditors' organizational form, legal liability, and reporting conservatism: evidence from China [J].Contemporary Accounting Research, 2012, 29 (3).

[8] Kong Ningning, Li Xue. Institutional Environment, Organizational Transformation of Accounting Firms and Audit Quality [J]. Journal of Audit \& Economics, 2016(02). 
[9] Pan Qi, Wen Quan. Corporate Governance Structure and Auditing Quality of Listed Companies - An Empirical Test Based on Listed Companies on GEM [J]. Modern Management Science, 2017(03).

[10] Jiang Yaoming, Xiao Jie, Zhang Linyi. The Advantage Concentration Effects of Internal Control Quality: From a Dual Perspective of Audit Quality and Audit Fees [J]. Journal of Central University of Finance \& Economics, 2017(07). 